This is an electronic reprint of the original article. This reprint may differ from the original in pagination and typographic detail.

Author(s): Laakkonen, Ilona; Taalas, Peppi

Title: $\quad$ Towards new cultures of learning: Personal learning environments as a developmental perspective for improving higher education language courses

Year: $\quad 2015$

Version:

Please cite the original version:

Laakkonen, I., \& Taalas, P. (2015). Towards new cultures of learning: Personal learning environments as a developmental perspective for improving higher education language courses. Language Learning in Higher Education, 5(1), 223-241. https://doi.org/10.1515/cercles-2015-0011

All material supplied via JYX is protected by copyright and other intellectual property rights, and duplication or sale of all or part of any of the repository collections is not permitted, except that material may be duplicated by you for your research use or educational purposes in electronic or print form. You must obtain permission for any other use. Electronic or print copies may not be offered, whether for sale or otherwise to anyone who is not an authorised user. 
Ilona Laakkonen* and Peppi Taalas

\title{
Towards new cultures of learning: Personal learning environments as a developmental perspective for improving higher education language courses
}

\begin{abstract}
This article provides readers with an understanding of the concept of the personal learning environment (PLE). It suggests that PLEs can be used in two complementary ways: as a developmental lens for integrating ICT and creating new pedagogical practices and digital literacies for academic language learning, and as a context in which learners can practise and develop core skills such as digital literacies, team and knowledge work, and interactional skills - skills that are needed for success in today's knowledge economy. The article places PLEs within the broader development related to the cultural changes brought on by the proliferation of Web 2.0 technologies participation, teamwork and co-design - and considers PLEs in relation to digital literacies and 21st-century skills. It then reports on a research-anddevelopment project that makes use of design-based research and creates tools and models for learner-centred technology integration on the basis of a rich set of data and experiments. The article presents theoretical as well as practical insights into implementing PLEs in higher education (HE) language centre teaching and outlines principles for implementation in formal education. It concludes by expressing the need to purposefully balance the structure provided by traditional approaches to learning against ways of organising it with the nearly unlimited resources and participatory aspects afforded by the new media.
\end{abstract}

Keywords: PLE (personal learning environment), digital literacies, core skills, pedagogy, development, social media

DOI 10.1515/cercles-2015-0011

*Corresponding author: Ilona Laakkonen, Centre for Applied Language Studies, University of Jyväskylä, Finland, E-mail: ilona.laakkonen@jyu.fi

Peppi Taalas, Language Centre, University of Jyväskylä, Finland, E-mail: peppi.taalas@jyu.fi 


\section{Introduction}

People today live in a world of ubiquitous digital technologies that constitute a significant part of the context for everyday life. Social media have become an increasingly important site for interaction and self-expression. Tapscott (2009), among others, maintains that the "net geners" are characterised by qualities such as integrity, collaboration and speed. Tapscott and Williams (2007: 52) describe young people as not being "content to be passive consumers" but as seeking to "increasingly satisfy their desire for choice, convenience, customization, and control by designing, producing, and distributing products themselves". Although this popular view of the Net Generation can be criticised in many ways (e.g. Selwyn 2011), universities are currently facing the need to integrate social media, to find new ways for assessing collaborative work, and to make sustainable and meaningful use of new technologies. In their recent book, A new culture of learning, Thomas and Seely Brown (2011: 17) articulate a question that encapsulates what is perhaps one of the core problems of 21st-century education: "What happens to learning when we move from the stable infrastructure of the twentieth century to the fluid infrastructure of the twenty-first century, where technology is constantly creating and responding to change?" Developing the 21st-century skills, or core skills that are needed for success in today's world, requires a level of personalisation that is higher than has been the tradition in formal education. From this perspective, learning environments that accommodate the individual needs and skill levels of the learners, and pedagogical choices that encourage learner ownership, agency and responsibility along with collaborative learning, group interaction and teamwork, are essential to the development of these core skills.

The personal learning environment (PLE), as a learner-centred approach to the integration of ICT or as a holistic ideological concept, can be seen as a promising route to addressing the question posed by Thomas and Seely Brown above. Since PLEs emerged in the e-learning conversation some 10-15 years ago, the discussion around the concept has been lively, and it is related to many of the hot topics in education today, including learner-centred pedagogy, self-regulated learning, new literacies, and the use of social media in education.

As the means, goals and contexts for communication evolve and expand, language education needs to be revisited and revised. Technological development and globalisation have affected how, why and when we use language and for what purpose. These changes have to be reflected in how language and the 
goals of formal learning are conceived of, in the more negotiated uses of language and in its different repertoires and genres (Pennycook 2010). Thorne and Reinhardt (2008: 560) state that for today's learners, "emerging literacies associated with digital media are highly relevant to their current and future lives as language users”. Lankshear and Knobel (2007) suggest that young people in the developed world share a whole new mindset that is different from the traditional, industrialist mindset, and is characterised by a sense of existence and spatiality that extends to the virtual space. This "post-industrial mindset" also incorporates much of what is often associated with Web 2.0 in terms of collaboration, production and participation. Lankshear and Knobel (2007) insist that bridging the "new" mindset of digital insiders and the "old" mindset of formal schooling is one of the major tasks educators face in today's society. On the borderline between formal and informal learning contexts - that is, between the old and new mindsets - there is a range of practices that could be capitalised on in language education. What takes place daily in the multiple - and cross-lingual - environments of social media is a living example of how new modes of communication generate new modes of expression, being together and using language.

The research and development focused on PLEs often approaches the concept as a technology. However, PLE pioneers and theorists such as Stephen Downes (2007) and George Attwell (2007, 2009) emphasise that the concept is about more than technology - it is about networked models of learning, learner involvement, participation and ownership. Although developing learning environments and technologies that could guarantee learner ownership across institutional boundaries is crucial, a more significant question lies not in technology per se, but in teaching and learning themselves: how can we make use of the learners' often informal PLEs in the context of formal education? What are the possibilities, constraints and solutions in implementing the rich layer of learner-centred Web 2.0 ideology in the context of formal higher education? What kind of forms can "PLEisation" take in the current reality of higher education? The present article seeks to answer these broad questions by first building a general understanding of the PLE as a perspective for developing education and associating it with digital literacies, and then, based on the findings and experience from a design-based research (DBR) process, by offering some suggestions for starting points for those interested in exploring with the PLE. The core argument is that 21st-century pedagogies are to be co-created and co-designed, and that in doing so we must not separate the pedagogical, technological and cultural developments but benefit from the cross-fertilization of ideas between them. 


\section{Background}

\subsection{Conceptualising the PLE}

There are two distinct research strands on PLEs (see Laakkonen 2011; Buchem et al. 2011): a technologically oriented one, which treats the PLE as technology, that is, as the ICT components of the learning ecosystem (e.g. van Harmelen 2008), and a more pedagogically oriented one (e.g. Attwell 2007; Downes 2007; Drexler 2010) that sees the PLE first and foremost as an ideational, holistic concept that cannot be separated from pedagogical practice and theories of learning. This view emphasizes the philosophical and ideological aspects of the approach and the rich theory evolving around this perspective may serve as a developmental lens, a learner-centred perspective on the use of ICTs and the design of learning, that can help in creating 21stcentury pedagogies and practices. As the PLE community is relatively active on the Internet, an active discussion and an array of conceptualizations may be found in journals and books, as well as on wikis and blogs and in various Internet document libraries and presentation sharing platforms. A recent, extensive review and analysis of the PLE literature is provided by Buchem et al. (2011), and a collection of PLE diagrams and visualisations can be found on the Edtechpostwiki.

In a rudimentary sense, a PLE can be seen as a loose collection of tools that help learners in their learning process by providing possibilities for searching, aggregating and scaffolding information as well as experimenting with it, by analysing and remixing ideas, by storing the knowledge learners gather and create, and by providing opportunities to present, represent and share ideas and knowledge (see Attwell 2009; Laakkonen 2011). As a general concept, the PLE started to take shape with the spread of social media use, thus reflecting their ideologies and practices (e.g. Downes 2007). Various digital networks, virtual environments, software applications and Internet resources usually constitute a major part of learners' informal learning environments. However, an individual learner's PLE can as well exist involving no technology at all. But within formal education it is still common to use a traditional learning management system (LMS) that has often been designed mainly for administrative purposes and that is not necessarily ideal for supporting learning. Although many LMSs have recently been developed to encompass the ideas of learner ownership and community building, ideologically the LMS and the PLE are irreconcilable. PLEs share the values inherent in Web 2.0: openness, agility, distribution of ownership and knowledge, or as Downes (2007: 19) states, "the fostering of 
social networks and communities, the emphasis on creation rather than consumption, and the decentralisation of content and control”.

An obvious and relevant question concerns the extent to which learner control and ownership can be actualized in the often rigid structures of formal education. Does implementing the PLE approach mean discarding LMSs, learning technologies and resources altogether? Peña-López and Adell (2010) and Laakkonen (2011) see that in the context of learning institutions, learner PLEs may also incorporate institutional aspects, resources and tools. The other side of the coin is that educational institutions, in turn, have to be "PLE-able, they have to rethink themselves, be more flexible, more open, and adapt to the new learning realities” (Peña-López \& Adell 2010).

\subsection{1st-century skills}

It should be understood that PLEs are regarded not only as an approach to learning and as an end in themselves, but as a context of learning that includes digital literacies, knowledge work, teamwork, communication and sharing, and meta-level skills such as self-directed learning and reflection, understanding of various types of media and forms of communication, and skills needed in multicultural and international contexts. This approach aligns well with the goal to develop 21st-century and core skills as an inherent part of any course work.

21st-century skills and core skills are both frameworks that help the rethinking and re-designing of learning outcomes and learning focuses. The Partnership for 21st Century Skills (2009: 3) sums up the requirements for learning environments, stating that in the 21st century they should be "support systems that organize the condition in which humans learn best - systems that accommodate the unique learning needs of every learner and support the positive human relationships needed for effective learning”. The Assessment and Teaching of 21st Century Skills (ATC21S) research project divides the skills into four broad but active categories:

- Ways of thinking: creativity, critical thinking, problem-solving, decisionmaking and learning

- Ways of working: communication and collaboration

- Tools for working: information and communications technology (ICT) and information literacy

- Skills for living in the world: citizenship, life and career, and personal and social responsibility 
Core skills, in turn, are an older concept used to define the goals of education and are usually more normatively and traditionally defined. The concept is mentioned in this article for the sake of the argument as these should not be too far removed from 21st-century skills. Core skills usually refer to the assessment of learning, reading, writing, oral communication and numeracy in various contexts.

In higher education language learning, and in language learning in general, promoting 21st-century skills requires a conscious expansion of language teaching practices. The focus needs to shift from teaching to learning, to promoting awareness and agency, and to thinking about language as a set of strategic skills and not only as mastering specific aspects of a language and its norms. In practice this means that language becomes an active notion, a process that takes on different forms depending on the purpose, medium and participants in a conversational context. Learners need to identify their own approach to language and find meaningful interfaces for learning and using languages. These interfaces exist for many students in their private sphere, but are seldom linked to formal education even if the multilingual resources would lend themselves to being integrated in goal-oriented language learning practices.

Of course, current assessment practices also need to reflect the idea of learning being about the process, about expanding one's personal language repertoires and cognitive skills, and about ways of working. The normative approaches to language as a set of rules and standards need to become more flexible, less indebted to the native speaker ideal and monolingual ideology while becoming more situational and participatory.

\subsection{Learning with PLEs: The question of digital literacy}

Expanding language learning practices aligns well with the underlying goal of PLEs because it means taking a step towards self-regulated learning and learner autonomy (Attwell 2007). When learners take control of their learning, it may help them to develop motivational patterns that lead to more effective learning results (Benson 2001). However, such a shift also requires that learners have the ability and skills to identify complex, real-life problems, and to construct the knowledge for solving them. Effective learning in the 21st century also entails skills and competencies related to the digital environment. For example, Beetham and Sharpe (2010) propose a framework for the development of digital literacies for learning, and link learning and thinking capabilities with general information, media capabilities and ICT. All these include learner capabilities concerning access, skills, practices and identities. 
So far several studies, especially Scandinavian ones, indicate that students' ICT skills are mainly acquired in informal learning contexts outside school, a situation that results in young learners seldom achieving the necessary digital competence to support their academic learning (see Ilomäki et al. 2012). This is the case especially with information processing skills: Kiili et al. (2008/2009), for example, found that the majority of upper secondary school students rarely evaluated the credibility of information, and that the evaluation of relevance was more important than the evaluation of credibility. Furthermore, the Internet is used infrequently and mainly for information search without students practising information organization and analysis, and students more often act as consumers rather than as producers and they work alone more often than they work collaboratively (Jedeskog and Nissen 2004).

According to Crook (2008), higher education needs "to play an important role in supporting students' supposedly self-directed activities - providing students with a good core and governance in 'arranging the furniture' of technology-based learning”. There are reported examples of developing good practices to foster digital skills in a school context. Drexler (2010) experimented with PLEs in her classroom with the goal of replacing the traditional textbook. She made use of customizable webpages (e.g. Symbaloo, NetVibes) to pull together information from various sources: social bookmarking sites, news readers, blogs, podcasts and digital notebooks. She proposed a model for a networked student and concluded that building PLEs leads to "inquiry-based learning and digital literacy, empowers the learner, and offers flexibility as new technologies emerge" (Drexler 2010: 369). Guth (2009) studied the potential of social software for teaching English as a foreign language and utilized blogs complemented with a feed reader and a social bookmarking site as PLEs. She concluded that the promise of the practice was not in the new technologies, but in the ideologies they incorporate, and that the PLE approach empowered the students and improved their learning skills. Walsh (2007) described an action research study in which the aim was to incorporate and extend the use of digital technologies from students' out-ofschool repertoires of practice to school activities. He reported changes, first, in his own understanding as he (the teacher) became better acquainted with the concept of multimodality and possibilities to include texts from digital youth culture into his own teaching. Second, he observed a shift in focus from traditional literacy instruction, in which students imitated literacy practices the teacher had modelled for them, to students becoming inventors/designers of new genres.

This section has presented an overview of PLEs in relation to digital literacies and a 21st-century skills framework, and discussed some earlier research on the use of ICT for learning and the application of PLEs in informal and formal learning contexts. This overview also serves as an argument for developing new 
pedagogical practices for language learning and teaching that would better include and encompass ideas of a more open approach to language, media use and learner engagement.

\section{The research process}

\subsection{The context and the project}

The research reported in this article was carried out at the Language Centre of the University of Jyväskylä. The Language Centre has a long tradition of pedagogical development and there is an established culture of inquiry and rethinking of current teaching practices. The general teaching goal of the institution is to employ multimodal pedagogies that help all students to become effective and convincing communicators in their specific professional fields. This approach links meaningful communication to real-life situations, supports individual and peer processes, and encourages creativity and selfregulation. In the Finnish higher education system, language and communication courses constitute a compulsory element of all degree programmes and students are drawn from a range of academic fields and backgrounds. In the Academic English language course in which this study was integrated, multiliteracies, ICT skills and transferable, lifelong learning and independent learning skills were cited as points of focus, along with the more language-oriented learning outcomes.

The PLE development was initiated as part of the F-SHAPE (Future Space for Shared and Personal Learning and Working) project (2010-2012), which had an R\&D focus on flexible learning solutions to fit the needs of adult learners and working life. Funded by Tekes (the Finnish Funding Agency for Innovation), the project explored the boundaries of various learning spaces: virtual spaces, personal and shared spaces, and their applicability in informal and formal learning contexts. PLEs were employed as an alternative to traditional approaches to learning environments and pedagogical development. The approach was explorative and open-ended, and the focus was on understanding the PLE as a pedagogical concept, pinpointing the possibilities and constraints for implementing the approach in the context of formal education, and on seeking sustainable solutions and development for merging informal and formal learning contexts and student-centred integration of ICTs. The main goal was to develop learning concepts, solutions and environments that respect the needs of the individual learner, while still acknowledging 
the interests of the organisation and supporting collaborative and communitybased aspects of learning.

\subsection{The method}

Design-based research (DBR) was employed as a general research strategy. DBR involves a goal-oriented, pragmatic and iterative view of research and proposes means for developing learning practices through empirical research (see Reinking and Bradley 2007). The strategy fits the project's goals because with its dual objectives it mediates a dialogue between research, theory and practice: (a) it aims at responding to local needs by developing new practices and environments, and (b) it strives to increase the general understanding of learning (Barab and Squire 2004).

DBR seeks to build knowledge that would be meaningful and usable in teaching. To complement the research at the University of Jyväskylä Language Centre, principles of contextual design (see Holtzblatt and Beyer 2013) were applied. This method has been used, for example, in user-centred design of software development and human-computer interaction as an alternative to traditional engineering. Contextual design involves the use of ethnographic methods as a means of aggregating data from the context as well as from users. In practice this means that the experiments were preceded by the collection of extensive background data (see Table 1) that helped to design experiments and models.

Design-based research and development typically take place in continuous cycles of design, enactment, analysis and redesign. As a young yet complex concept, there is still no coherent theory of PLEs, and the theory-building orientation of DBR was found to be suitable for exploring the implementation of such a concept in real-life educational settings. According to Joseph (2004), DBR uses the lens of design as a critical tool for pinpointing research questions. In other words it targets questions that are relevant to the implementation of the design itself. In the project described, the reification of the design also reveals the possibilities and constraints for the actualization of PLE ideology in the local context specifically, and in the context of formal education at large.

\subsection{The experiments and data}

At the beginning of the project, an ethnographic approach was used, because it is well suited to the ecological view of the research process and of learning. 
The early stages of research involved discussions with the staff, observations of compulsory courses, a student survey that mapped the use of social media and Internet resources for learning in formal and informal contexts, PLE mapping, and a questionnaire that concerned the use of digital resources to complete a writing assignment. This produced extensive background data that were used to create an understanding of the context and of the learners - an understanding that in turn formed the basis for the experiments. In addition, the solid understanding of the context enabled us to create models, PLE mapping tools and visions for future development, as presented below in section 4.

The exploration of PLEs in an HE context involved several experiments in which researchers, teachers and students worked together in multiple combinations. A summary of these can be found in Table 1 (below). In the context of courses that were compulsory (Academic English: Academic Reading; Professional Reporting), observations and interviews indicated that possibilities for building PLEs were scarce and limited by teaching schedules, organisation of space, lack of technology, and teacher-led pedagogical design. The context of elective (FinL2: Finnish as a second language) courses offered more freedom and resulted in various experiments conducted independently by the teachers (see Vaarala and Jalkanen 2010). The experiments were negotiated with the teachers involved, as the researchers were looking for sustainable change beyond the project and because earlier research indicated that this can best be created when teachers are able to justify ICT integration from a pedagogical point of view (e.g. International Association for the Evaluation of Educational Achievement 2006).

Tools for PLE mapping were developed and tested in a conference workshop in 2011 and in another workshop organised for a group of researchers involved in the study of ICT and pedagogy. These tools have since been used with students and were reported in Juntunen and Laakkonen (2014). The experiments indicated that learners find mapping their PLEs to be empowering and that instead of the customary PLE maps that mainly lay out the tools a person uses, organising the tools, environments and practices around a certain learning topic appears to be a more fruitful approach. The students' PLE maps may also be used as research data to increase the understanding of learners' formal and informal learning environments.

A separate PLE course, which was designed and taught by the researchers, formed a research entity of its own (see Table 1). It provided the chance to experiment with designing learning on the basis of PLE ideology and to address the questions of how digital literacies for professional learning can be taught and learned, as well as how far both personalised and participatory aspects of 


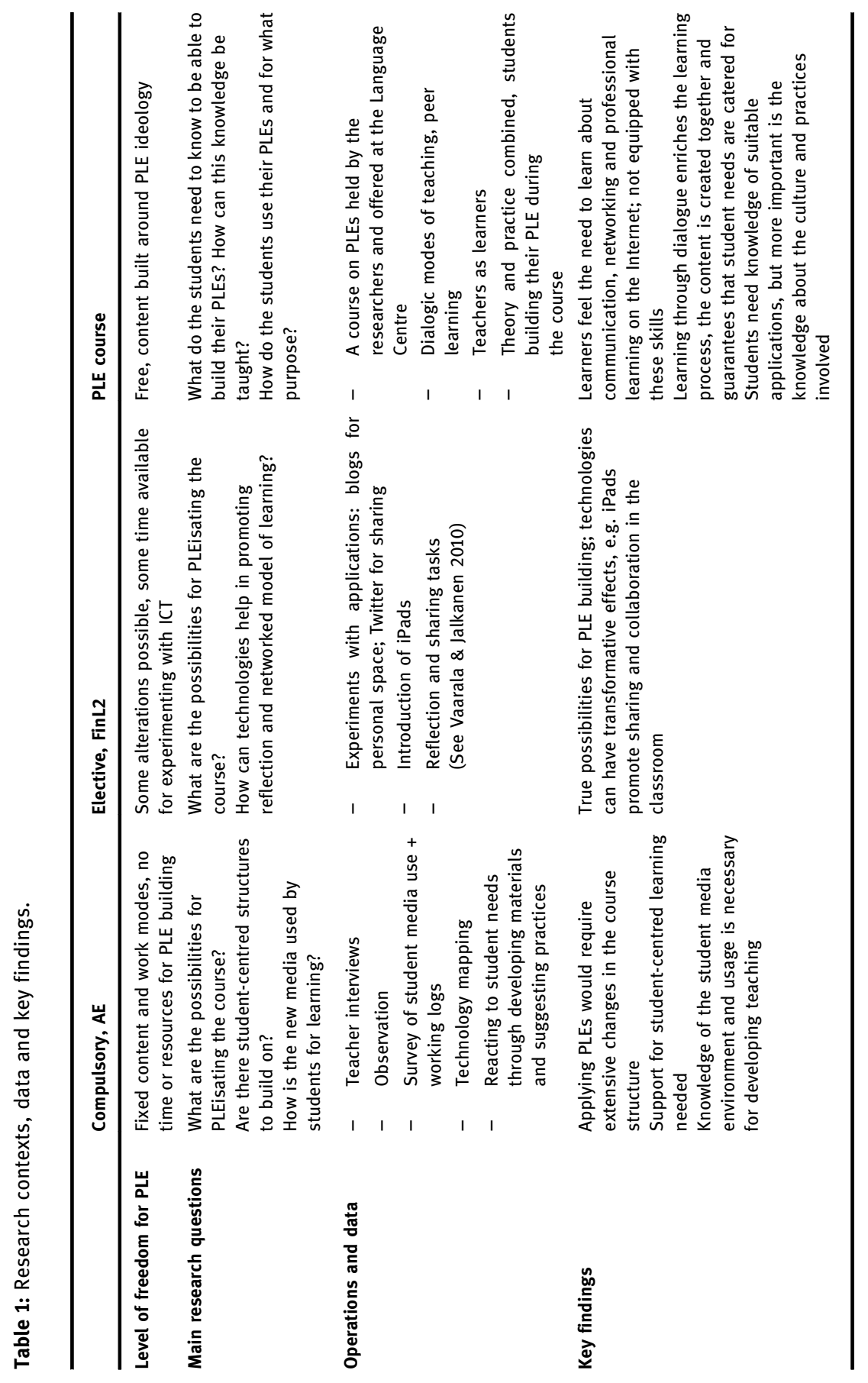


learning can be taken in informal education. The results from this experiment will be reported in Laakkonen (forthcoming). Table 1 summarises the research questions, operations and key findings from these three contexts.

\section{Results and discussion}

\subsection{Core skills as social and cultural knowledge}

The data collected during the project provide a rich and multilayered image of the possibilities for supporting and developing student-centred pedagogy through integration of ICT, and for combining students' knowledge of digital technologies with teachers' understanding of pedagogy to build digital literacy that fosters academic skills. Students need structure and support when adopting Web 2.0 tools and building their learning environments, knowledge of the resources and applications available, and skills that would guide them in goal-oriented and self-directed learning. The development of digital competence is best supported by pedagogical methods that include rich and integrated use of various technical tools as well as a wide range of activities that are based on complex and challenging tasks, such as students' own knowledge creation or product construction, solving multidisciplinary problems, collaborative activities or project work (Ilomäki et al. 2012). However, the background data (survey, observations, and discussions with the staff) indicate that opportunities for developing these competencies are not common in formal education, and teachers' pedagogical choices are often limited by the organisation of learning spaces; the availability of computers or tablets; the boundaries between subjects, courses and institutions; and occasionally by a lack of understanding of why and how to relinquish control and empower students in taking responsibility for their learning. Furthermore, competencies related to technology should not be seen as mere mechanical skills that involve using a specific software application, but as social and cultural knowledge. For example, Jenkins et al. (2005) believe that instead of access, the conversation around the digital divide should focus on the opportunities to participate and the cultural competencies and social skills required for full community involvement, such as new media literacies. Additionally, the methods for learning such skills require practising them in settings where multiple technological tools are used in an integrated way in authentic, complex tasks and for real-life purposes as much as possible. For example, the PLE course was built around the task of participating in professional 
networks for learning and communicating expertise, because many of the students were at the graduation stage. This orientation seemed to motivate the students and enhance their learning.

\subsection{Interplay between technology, pedagogy and content: steps towards PLEs}

Contextual design and DBR are future oriented in the sense that they seek to create and envision future transformations and workable designs. Based on the project data, concepts for implementing PLEs in a higher education context were created. To successfully integrate ICT and help students in building and maintaining their PLEs, a holistic approach is needed that combines the components and that respects the interplay between technology (applications and hardware), the teacher and the learner in designing learning and the learning content. Figure 1 below illustrates the steps that can lead to PLE implementation. The full implementation of the concept requires extensive changes in all of these areas, but the development can be started at any level. The model suggests that learners can be active designers of their learning environment. They can choose the tools they find to be the most suitable for the given tasks and they can have an active role in organising the tools for learning. In this approach, the choices students make are reflected in the pedagogy and task-design of a course as well as in language pedagogy in general.
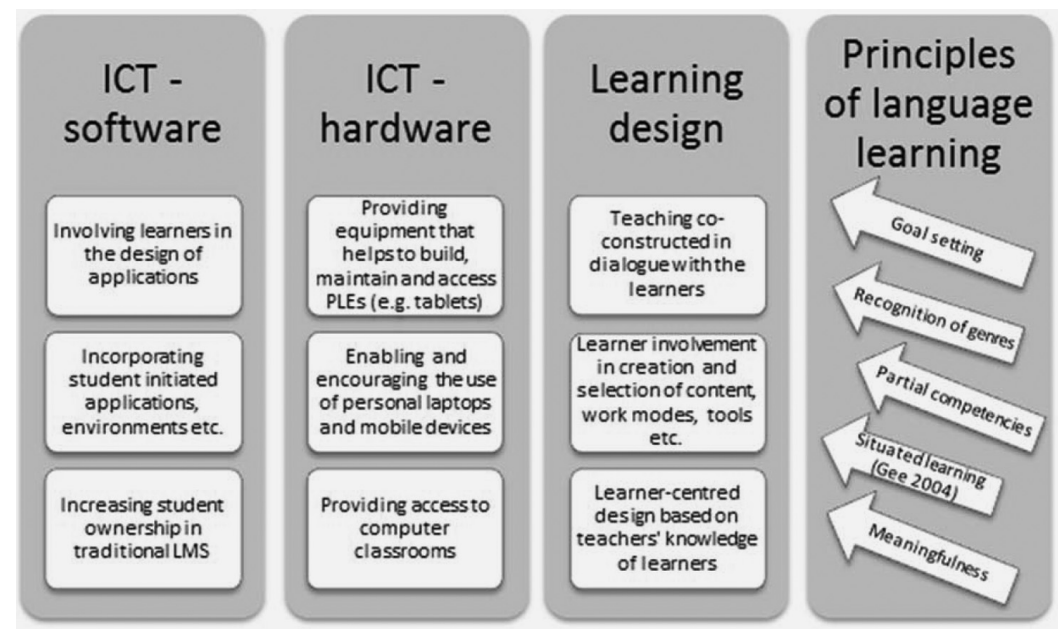

Figure 1: Steps in PLE development for higher education. 


\subsection{A model for PLE implementation throughout the studies}

Applying the PLE concept to a single course can be productive in, for example, developing learners' learning skills, an effect that Guth (2009) and Drexler (2010) have demonstrated. However, the PLE also offers a fruitful model for organising learning on an institution-wide basis, in a process that extends throughout university studies. Figure 2 below presents a model created during the project. The model is based on the increased understanding of "PLEisation" we gained through exploration. This serves as a basis for future development and outlines the PLE process that covers language and communication studies from the beginning of studies to graduation and beyond, and seeks to support the digital literacy skills as well as the communication skills of learners.

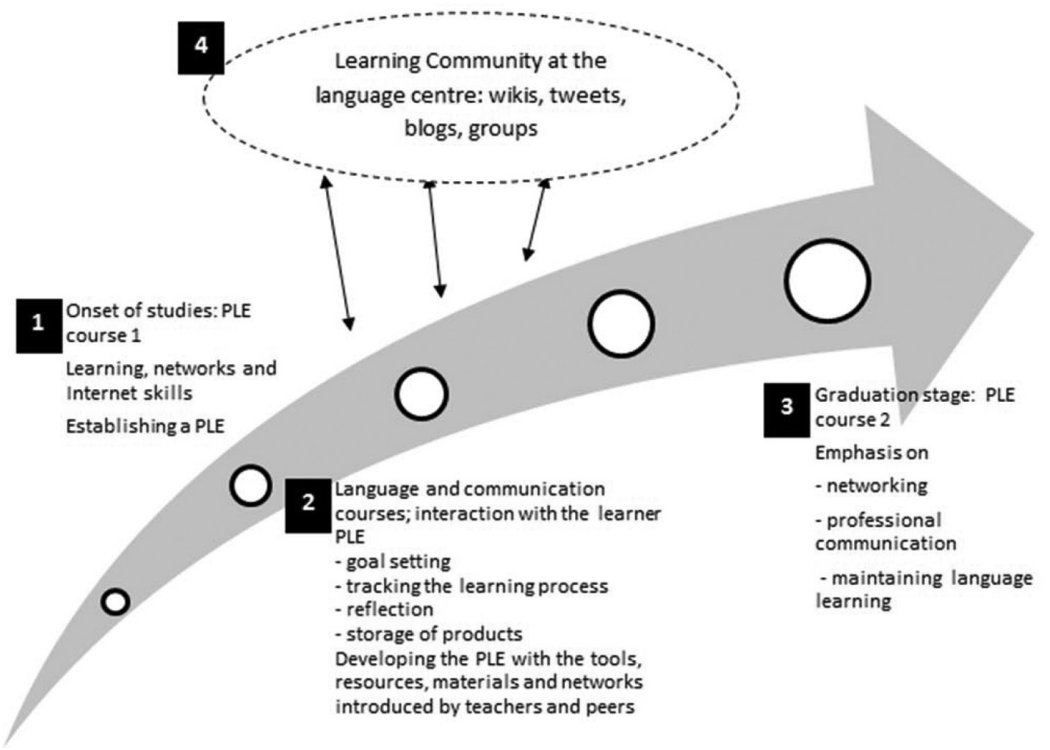

Figure 2: A model for integrating PLE throughout university studies.

In our model we suggest that (1) as students enter university, they are introduced to the concept of PLEs and learn how to build and maintain their own learning environment, which consists of the applications, systems and learning resources offered by the university as well as those elements that already constitute the learner's PLE. Learners also need basic instruction in information literacy and learning skills. 
The second phase (2) extends through the study of language and communication skills, independent of the languages students study. Students maintain their own PLEs, in which they set their long-term goals, reflect upon their learning, edit the goals as they progress, store the products and content they have created, and share them with others if they choose. The key idea is that, before every course, learners view the intended learning outcomes of the specific course and evaluate what those outcomes mean in relation to their general learning goals, in relation to the resources they need and the networks that can help them to achieve those goals. In addition, every course contributes to the student PLE with the tools, resources and networks introduced to the students by the teacher, found by the students themselves or learned from others.

The experiment with the PLE course showed that as graduation approaches, students start to feel the need to learn about communicating their professional expertise, to build their networks, and to find ways of maintaining their learning in their working life. It also revealed that they feel that their studies do not equip them with adequate skills. Thus the model proposes that (3), close to graduation, a specific course on professional communication and learning on the Internet is organised. During this course students would focus on recognising their own competence, learning about the culture of Internet communities, and communicating and participating in professional networks.

In spite of its name, the PLE is almost more about social and networked learning than it is about individual learning. The fourth component of the model is the wider community that is built and the content that is co-created and shared in the course of the individual's studies, such as wikis, course blogs or discussion threads. These contribute to the common learning environment (4), or virtual space, that is available to all students and teachers. It should be noted that this environment is not necessarily an entity, such as a specific LMS, but that it is created from the communication that occurs in various applications and networks.

\section{Conclusions}

Referring to Crook's (2008) statement on the responsibility of higher education to provide students with the skills they need in order to use technology for their self-directed activities -what else could this role be than building PLEs and developing digital literacies? The new culture of learning views learning "in terms of an environment - combined with the rich resources provided by the digital information network - where the context in which learning 
happens, the boundaries that define it, and the students, teachers, and information within it all coexist and shape each other in a mutually reinforcing way" (Thomas and Seely Brown 2011: 35). Learners are increasingly involved in defining problems and goals, designing learning, and finding individually meaningful modes of participation. The PLE as an approach to integrating ICT in learning can help to develop the pedagogies and literacies needed in the 21st century.

The experience of implementing the PLE as a developmental lens was promising - as long as the premise is accepted that to be effective, the development of new pedagogies for the digital age requires extensive work on many levels and in several fields simultaneously. Working on the creation of suitable pedagogies and practices is worthwhile, and new applications are to be expected in the future that will encourage the development of flexible learning spaces that are personal as well as shared. Although the project showed that for the time being there are many challenges to the "PLEisation" of higher education, it is possible that small but simultaneous steps on several fronts are exactly how progress is best made instead of in large-scale but often short-lived interventions. Based on our results, we encourage language teachers to inquire into learners' media use and practices, and to engage learners in the design of their learning environment and process. Because they use multimodal learning environments, these practices may help learners to make their learning and thinking visible, and thus enable teachers to deepen their understanding of how to facilitate the learning process. These environments also make it possible to document different phases of work and make it easier to embed new forms of assessment in the course structure. As new practices are created, a new culture of learning may gradually emerge, in which the learning is designed and cocreated by students and teachers, students bringing to the table their understanding of the new media and their culture, and the teachers their pedagogical, didactic and content knowledge.

This article has explored some of the forms that the PLE can take in the context of formal education. The product, whether an actual virtual environment or an abstraction in a learner's mind, can benefit learning, teaching and pedagogical development only when it is accompanied by a solid pedagogical structure from goal-setting to assessment. More research is needed on how this approach can benefit learning and teaching in higher education and on what its can contribute to the theory of learning in the digital age. There is a need to balance the structure that traditional approaches to the organisation of learning provide in educational institutions against the freedom that the nearly unlimited resources of the new media afford (Thomas and Seely Brown 2011). This balance of structure and freedom is, in essence, the promise of PLEs. 


\section{References}

ATC21S. Assessment and teaching of 21st century skills. http://atc21s.org/

Attwell, Graham. 2007. Personal learning environments - the future of eLearning? eLearning papers 2(1). http://senior.googlecode.com/files/media11561-1.pdf (accessed 18 December 2014).

Attwell, Graham. 2009. Personal Learning Environments: The future of education? Slidecast http://www.slideshare.net/GrahamAttwell/personal-learning-enviroments-the-future-ofeducation-presentation (accessed 18 December 2014).

Barab, Sasha \& Kurt Squire. 2004. Design-based research: Putting a stake in the ground. The Journal of the Learning Sciences 13(1). 1-14.

Beetham, Helen \& Rhona Sharpe. 2010. Digital literacy framework. The Design Studio, JISC. http://jiscdesignstudio.pbworks.com/w/page/46740204/Digital\%20literacy\%20 framework (accessed 8 September 2014).

Benson, Paul. 2001. Teaching and researching autonomy in language learning. Harlow, UK: Pearson Education.

Buchem, Ilona, Graham Attwell \& Ricardo Torres. 2012. Understanding Personal Learning Environments: Literature review and synthesis through the Activity Theory lens. http:// www.scribd.com/doc/62828883/Understanding-Personal-Learning-EnvironmentsLiterature-review-and-synthesis-through-the-Activity-Theory-lens (accessed 26 May 2014).

Crook, Charles. 2008. Theories of formal and informal learning in the world of Web 2.0. In Sonia Livingstone (ed.), Theorising the benefits of new technology for youth: Controversies of learning and development, 31-34. Economic and Social Research Council, University of Oxford, and London School of Economics. http://eprints.Ise.ac.uk/33821/1/ Theorising_the_benefits_of_new_technology_for_youth.pdf (accessed 26 May 2014).

Downes, Stephen. 2007. Learning networks in practice. Emerging Technologies for Learning 2. Coventry, UK: British Educational Communications and Technology Agency. http://www. downes.ca/files/Learning_Networks_In_Practice.pdf (accessed 26 May 2014).

Drexler, Wendy. 2010. The networked student model for construction of personal learning environments: Balancing teacher control and student autonomy. Australasian Journal of Educational Technology 26(3). 369-385.

Edtechpostwiki. http://edtechpost.wikispaces.com/PLE+Diagrams (accessed 26 May 2014).

Guth, Sarah. 2009. Personal learning environments for language learning. In Michael Thomas (ed.), Handbook of research on Web 2.0 and second language learning, 451-471. Hershey, PA: IGI Global.

Holtzblatt, Karen \& Hugh R. Beyer. 2013. Contextual design. In Mads Soegaard \& Rikke Friis Dam (eds.), The encyclopedia of human-computer interaction, 2nd edn. Aarhus, Denmark: The Interaction Design Foundation. https://www.interaction-design.org/encyclopedia/ contextual_design.html (accessed 5 Septempber 2014).

Ilomäki, Liisa, Peppi Taalas \& Minna Lakkala. 2012. Learning environment and digital literacy: A mismatch or a possibility from Finnish teachers' and students' perspective. In Peter Trifonas (ed.), Living the virtual life: Public pedagogy in a digital world, 63-78. New York: Routledge.

International Association for the Evaluation of Educational Achievement. 2006. Second Information Technology in Education Studies 2006. http://www.sites2006.net/ (accessed 26 May 2014). 
Jedeskog, Gunilla \& Jörgen Nissen. 2004. ICT in the classroom: Is doing more important than knowing? Education and Information Technologies 9. 37-45.

Jenkins, Henry, with Ravi Puroshotma, Katharine Clinton, Margaret Weigel \& Alice J. Robinson. 2005. Confronting the challenges of participatory culture: Media education for the 21st century (Building the new field of digital media and learning). Chicago, IL: MacArthur Foundation. http://www.newmedialiteracies.org/wp-content/uploads/pdfs/ NMLWhitePaper.pdf (accessed 26 May 2014).

Joseph, Diana. 2004. The practice of design-based research: Uncovering the interplay between design, research, and the real-world context. Educational Psychologist 39(4). 235-242.

Juntunen, Merja \& Ilona Laakkonen. 2014. PLE - tapa oppia [PLE - a way to learn]. In Häkkinen, Päivi \& Jarmo Viteli (eds.), Pilvilinnoja ja palomuureja - Tulevaisuuden oppimisen ja työnteon tilat. F-SHAPE-projektin satoa [Clouds and firewalls. Findings from the F-SHAPE project], 59-81. Jyväskylä: Finnish Institute for Educational Research. https://ktl.jyu.fi/ julkaisut/julkaisuluettelo/julkaisut/2014/D109.pdf (accessed 8 September 2014).

Kiili, Carita, Leena Laurinen \& Miika Marttunen. 2008/2009. Students evaluating Internet sources: From versatile evaluators to uncritical readers. Journal of Educational Computing Research 39(1). 75-95.

Laakkonen, Ilona. 2011. Personal learning environments in higher education language courses: An informal and learner-centred approach. In Sylvie Thouësny \& Linda Bradley (eds.), Second language teaching and learning with technology: Views of emergent researchers, 9-28. Dublin: Research-publishing.net. http://research-publishing.net/publication/ chapters/978-1-908416-00-1/2_IlonaLaakkonen.pdf (accessed 26 May 2014).

Laakkonen, Ilona. Forthcoming. Doing what we teach: Developing digital literacies for personal learning environments through learner-engagement. In Juha Jalkanen, Elina Jokinen \& Peppi Taalas (eds.), Voices of pedagogical development: Expanding, enhancing and exploring higher education language learning. Dublin: Research-publishing.net. (Working titles.)

Lankshear, Colin \& Michele Knobel. 2007. Sampling "the new" in new literacies. In Michele Knobel \& Colin Lankshear (eds.), A new literacies sampler, 1-24. New York: Peter Lang.

Partnership for $21^{\text {st }}$ Century Skills. 2009. 21st century learning environments: White paper. http://www.p21.org/storage/documents/le_white_paper-1.pdf (accessed 26 May 2014).

Peña-López, Ismael \& Jordi Adell. 2010. The dichotomies in personal learning environments and institutions. A presentation at the PLE Conference 2010. http://ictlogy.net/20100712-thedichotomies-in-personal-learning-environments-and-institutions/ (accessed 26 May 2014).

Pennycook, Alastair. 2010. Language as a local practice. New York: Routledge.

Reinking, David \& Barbara A. Bradley. 2007. On formative and design experiments: Approaches to language and literacy research. New York: Teachers' College.

Selwyn, Neil. 2011. Social media in higher education. The Europa World of Learning, 62nd edn. London: Routledge. http://www.educationarena.com/pdf/sample/sample-essay-selwyn. pdf (accessed 26 May 2014).

Tapscott, Don. 2009. Grown up digital: How the net generation is changing your world. New York: McGraw-Hill.

Tapscott, Don \& Anthony D. Williams. 2007. Wikinomics. New York: Atlantic.

Thomas, Douglas \& John Seely Brown. 2011. A new culture of learning: Cultivating the imagination for a world of constant change. CreateSpace (http://www.createspace.com).

Thorne, Steven L. \& Jonathon Rheinhardt. 2008. "Bridging activities", new media literacies, and advanced foreign language proficiency. CALICO Journal 25(3). 558-572. 
Vaarala, Heidi \& Juha Jalkanen. 2010. Changing spaces, expanding mindsets: Towards L2 literacies on a multimodal reading comprehension course. Language Value 2(1). 68-99. van Harmelen, Mark. 2008. Design trajectories: Four experiments in PLE implementation. Interactive Learning Environments 16(1). 35-46.

Walsh, Christopher. 2007. Creativity as capital in the literacy classroom: Youth as multimodal designers. Literacy 41(2). 79-85.

\section{Bionotes}

\section{Ilona Laakkonen}

Ilona Laakkonen is a researcher, teacher and developer at the University of Jyväskylä, currently working in the Division of Strategic Planning. Her research interests are future learning environments, multimodal pedagogies, and changing practices in language teaching and learning. Her focus is on learner-centred design and digital literacies needed for life-long learning.

\section{Peppi Taalas}

Peppi Taalas is director of the Language Centre at the University of Jyväskylä. Her research interests are multimodal language pedagogies and technology-integrated teaching and learning. She has extensive experience of national and international research and development projects in the area of educational change, staff development and multimodal language learning environments. Her research foci are: technology supported learning, learning designs, teacher and school development, and affordances of technology and media for learning. 